\title{
Mathematical Modeling the Dynamics of the Bottom Sediments Granulometric Composition in the Balaklava Bay Affected by the Wind Waves
}

\author{
K. I. Gurov ${ }^{凶}$, V. V. Fomin \\ Marine Hydrophysical Institute of RAS, Sevastopol, Russian Federation \\ 凶gurovki@gmail.com
}

Purpose. Based on the mathematical modeling methods, influence of the wind waves on redistribution of the sand fractions in the semi-closed estuary-type water area is estimated using the Balaklava Bay as an example.

Methods and Results. A two-dimensional version of the XBeach model with a constant grid spacing $10 \mathrm{~m}$ was used. The characteristics of wind waves were preset using the JONSWAP spectrum. The calculations were carried out for a storm event lasting about 12 hours once a year. The in-situ data on the particle size distribution in the bottom sediments resulted from the monitoring observations in the Balaklava Bay region was used in the numerical experiments.

Conclusions. The results of modeling showed that the basic determining factors regulating the sediments movement were the depth and the bottom slope. It is noted that changing of the bottom inclination angle between the isobaths 6-7 and 7-8 m leads to deposition of the large and medium fractions, and in the area between the isobaths $9-10$ and 10-12 $\mathrm{m}$ - to accumulation of fine sand. It was revealed that in the Balaklava Bay water area, the main redistribution of sand material caused by the storm waves took place within the southern basin, as well as at the bay exit in the coastal zone of the Megalo-YaloGulf. This is primarily determined by the features of the Balaklava Bay coast orography, namely, the knee-shaped narrowness separating the northern and southern basins. Nevertheless, in the isolated northern part of the Balaklava Bay being affected by the storm waves, insignificant dynamics of sand material was observed. The fractions of bottom sediments are redistributed from the western coast to the central part of the basin and to the eastern coast of the bay.

Keywords: Balaklava Bay, bottom sediments, XBeach model, granulometric composition, storm deformations

Acknowledgements: the investigation was carried out within the framework of the state task on theme No. 0555-2021-0005 "Complex interdisciplinary investigations of the oceanologic processes conditioning functioning and evolution of the Black and Azov seas' ecosystems of the coastal zones" ("Coastal investigations" code) and at the RFBR partial support within the framework of the research projects No. 18-05-80035 and 18-45-920007.

For citation: Gurov, K.I. and Fomin, V.V., 2021. Mathematical Modeling the Dynamics of the Bottom Sediments Granulometric Composition in the Balaklava Bay Affected by the Wind Waves. Physical Oceanography, [e-journal] 28(1), pp. 78-89. doi:10.22449/1573-160X-2021-1-78-89

DOI: $10.22449 / 1573-160 \mathrm{X}-2021-1-78-89$

(C) K. I. Gurov, V. V. Fomin, 2021

(C) Physical Oceanography, 2021

Introduction. Due to its unique natural and climatic conditions and morphometric characteristics, the Balaklava Bay occupies a special place among the bays of the Sevastopol region. At present, it is actively developing as a port area for small vessels, which several times increases the anthropogenic pressure on the bay waters and may lead to a deterioration of its ecological state. Complex construction in the coastal zone, a large amount of organic matter inflowing with municipal and stormwater runoffs, negatively affect the ecological integrity of this 
section of the coastal zone. Maintaining this integrity is important for the development of the resort and recreational complex.

The main stages of the study of the Balaklava Bay water area, as well as the modern description of the structure and temporal variability of morphometric, hydrophysical, hydro-optical, hydrochemical, hydrobiological fields obtained on the basis of the analysis of expeditionary observations data, and the assessment of the degree of water pollution are presented in [1]. Little attention is paid to bottom sediments in this monograph. Nevertheless, the study of bottom sediments in the Balaklava Bay started already at the end of the $19^{\text {th }}$ century [2]. The first modern information related to the physical and chemical properties of bottom sediments, composition and quantitative characteristics of macrozoobenthos [3]. At present, much attention is paid to the pollution of the bay bottom sediments with organic substances [4, 5] and heavy metals [6, 7]. In works [5, 7] it is noted that the fractional composition in the surface layer of bottom sediments has changed, primarily due to an increase in the proportion of fine-grained material.

At present, it is especially important to study the regional features of the coastal zone relief dynamics and the redistribution of sediment fractions in coastal areas using a wide range of mathematical models and calculation methods [8-13]. Despite the fact that the work on mathematical modeling of the of water circulation features $[14,15]$ for the water area of the Balaklava Bay was carried out, the work on the modeling of bottom sediments dynamics in the area under study was not carried out.

The purpose of this work is to assess the effect of wind waves on the redistribution of sand fractions using the example of the Balaklava Bay (a semienclosed estuary-type water area) and the nearby areas of the Megalo-Yalo Gulf. Previously, the work in this direction was carried out by the authors for a section of the coastal zone of the Southern coast of Crimea in the area of the Limensky Gulf [16].

Characteristics of the area under study. The Balaklava Bay is located on the southwestern coast of Crimea between Fiolent Cape and Aya Cape. The water area of the bay is divided on the basis of the bottom morphometry and the configuration of the shores into a shallow part at the top of the bay, a central part, a southern deep-sea extension and a knee-like narrowness connecting the last two parts.

According to [17], the area of the Megalo-Yalo Gulf and the Balaklava Bay included in it belong to the tectonic structure of the mountain Crimea meganticlinorium. The Balaklava Bay is a characteristic ria-type ingress bay [18]. Modern morphometric characteristics of the bay: maximum depth at the entrance section $34.2 \mathrm{~m}$, average depth $12.5 \mathrm{~m}$ (47\% of the bay water surface is located above 4-12 m depths), length along the fairway $1410 \mathrm{~m}$, width at the entrance section $200 \mathrm{~m}$, the smallest width is $95 \mathrm{~m}$, the coastline length is $3.33 \mathrm{~km}$. A kneeshaped narrowness in the central part divides the bay into two approximately equal water areas - the northern and southern basins, which differ in the morphometry and hydrodynamics features [1].

As is known [19], in the Balaklava region the mean annual wind velocity reaches $6 \mathrm{~m} / \mathrm{s}$. The maximum wind velocity and wave intensity are observed in 
the cold season. The prevailing winds are of southern (31\%), northern (29\%) and northeastern (22\%) directions.

The central and northern parts of the bay are distinguished by their isolation from the wind impact. Storms are typical only for the southern open and deepwater part with strong southern winds. According to observations from work [19], in the Balaklava Bay the maximum frequency of occurrence is observed in the waves, including storm ones, of the southern (about $30 \%$ ), southwestern (17.2 \%) and southeastern (10.7\%) directions (i.e. from the sea). In the autumn, during the passage of Mediterranean cyclones, the winds of the southern directions can reach $30 \mathrm{~m} / \mathrm{s}$ and form the waves of up to $7 \mathrm{~m}$ height [19].

Mathematical model and input data. In order to study the features of wind wave impact on the redistribution of the bottom sediment fractions in the Balaklava Bay area, the complex morphodynamic model XBeach was applied [20]. A twodimensional version of the model with a constant grid step of $10 \mathrm{~m}$, which allows to calculate wind waves, wind-wave currents and bottom deformations simultaneously, was used. The data on the bottom topography were obtained by digitizing the bathymetric map of the Balaklava Bay and the adjacent water area. The dimensions of the computational domain were $1.8 \times 1.3 \mathrm{~km}$. The region included the water area of the Balaklava Bay and a part of the coastal zone of the Megalo-Yalo Gulf (Fig. 1). Numerical modeling was performed for storms lasting 12 hours. Free passage conditions were set at the western and eastern liquid boundaries [20].

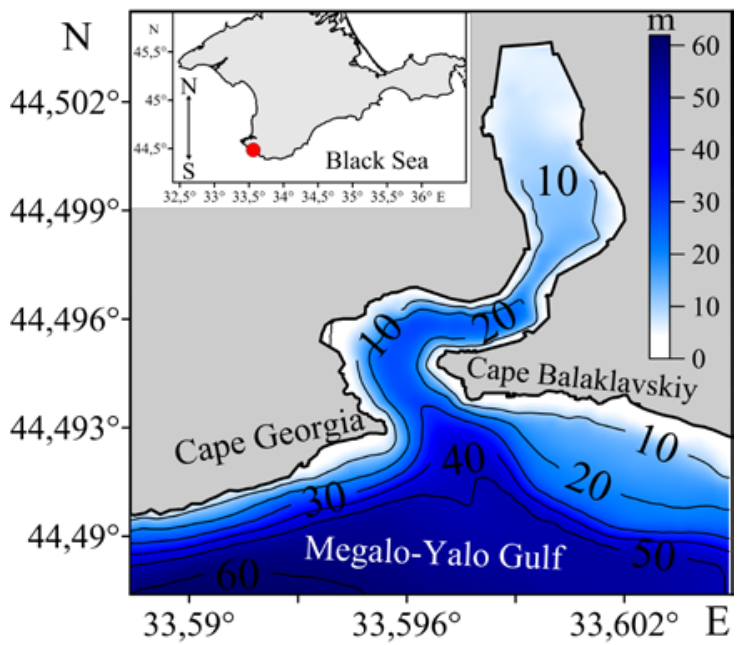

F i g. 1. Location of the research area and the bottom topography of the Balaklava Bay

To determine the characteristics of wind waves at the southern boundary of the computational domain, we used a two-dimensional frequency-angular spectrum of the form [20]

$$
E(\sigma, \theta)=F(\sigma) \cdot \psi(l) \cdot \cos ^{2 l}\left(\frac{\theta-\bar{\theta}}{2}\right), \quad \psi(s)=\frac{2^{2 l-1}}{\pi} \frac{\Gamma^{2}(l+1)}{\Gamma(l s+1)},
$$


where $\sigma$ is a circular wave frequency; $\theta$ is the direction of waves; $l$ is the indicator of directional spreading coefficient degree; $\bar{\theta}$ is mean wave direction; $\Gamma$ is gamma function; $F(\sigma)$ is a frequency spectrum JONSWAP, determined in the form

$$
F(\sigma)=0,307 \alpha_{F} \frac{h_{s}}{\sigma_{p}} \frac{\exp \left(-1,23 a^{-4}\right)}{a^{5}} s^{\beta} .
$$

Here $\quad \alpha_{F}=0.0131 ; a=\sigma / \sigma_{p} ; \beta=\exp \left(-\frac{(a-1)^{2}}{2 b}\right) ; b=\left\{\begin{array}{l}0.07 \text { at } a \leq 1 \\ 0.09 \text { at } a>1\end{array} ; \quad h_{s}\right.$ is a height of significant waves; $\sigma_{p}$ is circular frequency of the waves corresponding to the peak in the spectrum; $\tau_{p}=2 \pi / \sigma_{p}$ is a peak period; $s=1000$ is a parameter of the spectrum peakiness. This value of $s$ was chosen to set the spectrum with low angular scattering [20, p. 62], which makes the XBeach model easier to use.

At the southern boundary of the computational domain $h_{s}$ and $\tau_{p}$ in formula (1) were taken equal to $5 \mathrm{~m}$ and $10 \mathrm{~s}$, respectively. In [21], based on retrospective calculations of the waves in the Black Sea for 1979-2019 according to the SWAN model, it is shown that the adopted values of $h_{s}$ and $\tau_{p}$ correspond to the storms that are possible in the Balaklava Bay area once a year. Numerical experiments were carried out for three mean directions of waves $\bar{\theta}$ on the computational domain southern boundary (southern, south-south-west, and south-south-east). According to [21], the south-southwest direction corresponds to the most intense storm situations in the Balaklava Bay area.

In the first cycle of numerical experiments, a homogeneous combination of particle size fractions was used as the initial parameters for the sediment. The content of coarse-grained material was $25 \%$, medium-grained material - $10 \%$ and finegrained material $-65 \%$. The selected values satisfied the average values for each fraction of the sediment and displayed the proportional ratio of the particle size distribution at the initial time.

For the second series of numerical experiments, a combination of three fractions, the spatial distribution of which is based on the results of the Marine Hydrophysical Institute monitoring observations carried out in 2005, 2015, 2018 [4-7, 22] was used. The granulometric composition of bottom sediments was specified as a mixture of three components (fine gravel and coarse-grained sand, medium-grained sand, finegrained sand) distributed with different ratios of volumetric concentrations in different parts of the studied water area. A generalized characteristic of the granulometric composition of the Balaklava Bay area bottom sediments is given in the Table.

In XBeach model each bottom sediment class is characterized by the volumetric concentration $p_{i, j}(x, y, t)$ where $i$ is the sediment class; $j$ is the number of the sediment layer; $x, y, t$ are the spatial coordinates and time. At the initial moment $(t=0)$, the composition of the layer was specified in the form

$$
p_{i, j}(x, y, 0)=\bar{p}_{i, j}(x, y),
$$

where $\bar{p}_{i, j}(x, y)$ are the predetermined volume concentrations. 
Characteristics of the bottom sediments particle size distribution in the Balaklava Bay region

\begin{tabular}{l|c|c|c}
\hline \multicolumn{1}{c|}{ Fraction } & $D_{90,} \mathrm{~mm}$ & $D_{50}, \mathrm{~mm}$ & $D_{15}, \mathrm{~mm}$ \\
\hline Fine gravel and coarse-grained sand & 1.5 & 0.800 & 0.65 \\
Medium-grained sand & 0.5 & 0.375 & 0.25 \\
Fine-grained sand and aleurite & 0.2 & 0.130 & 0.10 \\
\hline
\end{tabular}

The average volumetric concentration for each sediment fraction was calculated by the formula $(i=1,2,3)$

$$
p_{i}(x, y, t)=\frac{\sum_{j=1}^{n d} p_{i, j}(x, y, t) \cdot \Delta z_{j}(x, y, t)}{\sum_{j=1}^{n d} \Delta z_{j}(x, y, t)},
$$

where $\Delta z_{j}$ is a thickness of each sediment layer. With regard to formula (2) the median diameter of sediment is represented in the form

$$
d(x, y, t)=\sum_{i=1}^{n g d} d_{50}(i) \cdot p_{i}(x, y, t),
$$

where ngd is an amount of sediment classes. In our case three sediment classes, expressed as three fractions, were used.

Further, using relation (3), the relative average diameter of the sediment was estimated:

$$
D(x, y, t)=100 \%\left(\frac{d(x, y, t)}{d(x, y, 0)}-1\right) .
$$

Modeling results and discussion. As is shown by the numerical modeling results, in the water area of the Balaklava Bay the main redistribution of sandy material caused by storm surges occurs only in the southern part, as well as at the exit from the bay in the coastal zone of the Megalo-Yalo Gulf. First of all, this is determined by the features of the coastal orography, namely the knee-like narrowness separating the northern and southern parts of the bay.

It has been confirmed that the main determinants of material movement are the depth and bottom inclination. According to [23], if the underwater coastal slope is composed of sediments of various sizes, the waves tend to distribute the material in descending order of size from the coast, while the bottom inclination angle will be determined by the composition of the material in this area. In this work, it was found that a sharp change in the bottom inclination (from 0.05 to 0.125 ) between 6-7 and 7-8 $\mathrm{m}$ isobaths first leads to the precipitation of large and medium fractions, and in the area between 9-10 and 10-12 isobaths (0.125-0.17) - to precipitation of an already fine-grained fraction. The redistribution of sandy material begins to manifest itself immediately after the onset of wave effect. 
In Fig. 2 and 3 the spatial distributions of the volumetric concentrations of sand fractions in the Balaklava Bay area after 6 and 12 hours of the effect of storm waves of different directions are shown.

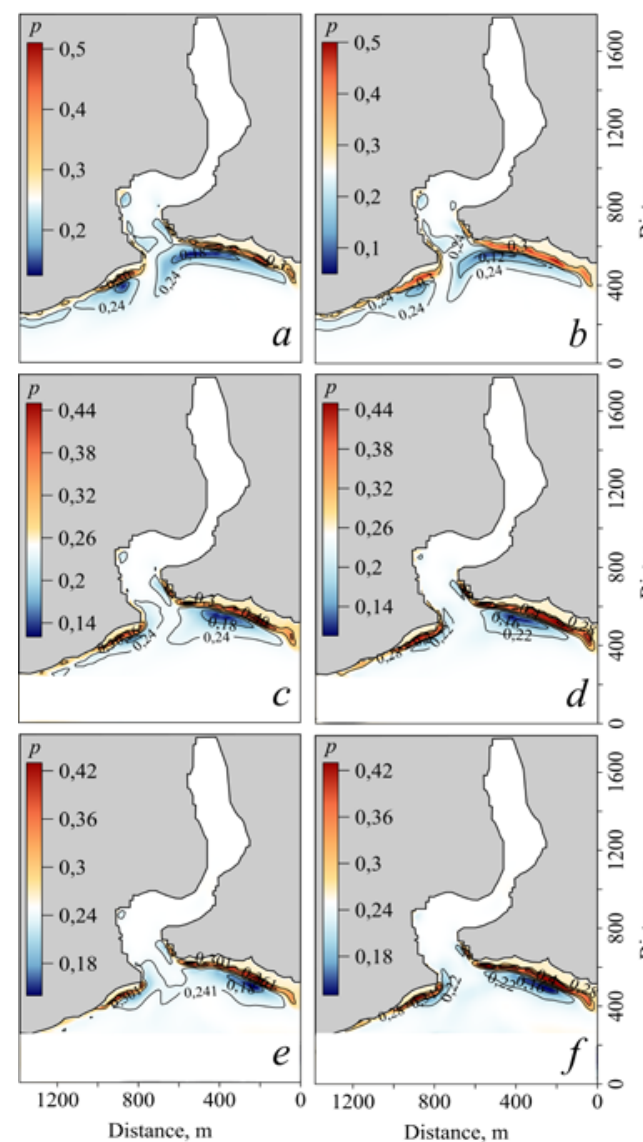

F i g. 2. Spatial distribution of the coarsegrained sand fraction volume concentrations at the waves of the south-southeast $(a, b)$, south $(c$, $d)$ and south-southwest $(e, f)$ directions in $6(a, c$, $e)$ and $12(b, d, f)$ hours after the waves began

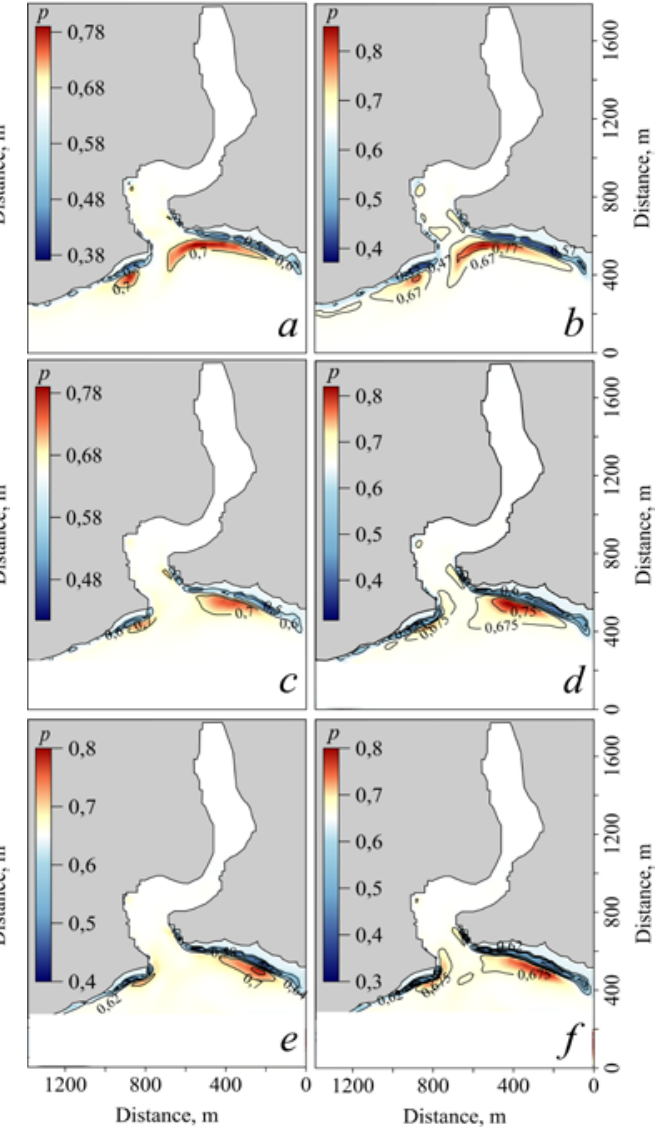

F i g. 3. Spatial distribution of the fine-grained sand fraction volume concentrations at the waves of the south-southeast $(a, b)$, south $(c, d)$ and south-southwest $(e, f)$ directions in $6(a, c, e)$ and $12(b, d, f)$ hours after the waves began

Analysis of the presented fields shows that under effect of storm waves, coarsegrained and medium-grained material is distributed in the coastal zone and in the areas adjacent to the capes. The location, as well as the width of the areas of coarse-grained material maximum concentrations in the western and eastern parts of the studied coastal zone section varied with a change in the direction of waves (Fig. 2).

The maximum concentrations of coarse-grained material are traced between 5$8 \mathrm{~m}$ isobaths in the western part and 6-10 in the eastern part. Near the western coast, the accumulation of coarse and medium grain size material occurs up to $4 \mathrm{~m}$ isobath. At great depths, the content of coarse-grained fractions decreases, reaching its minimum values within $12-18 \mathrm{~m}$ isobaths. In the area of the capes, due to a sharp increase in depth, the accumulation of coarse-grained material can be traced up to $15-17 \mathrm{~m}$ isobaths. With an increase in the wave impact duration, the amount of transported material increases and the strip of coarse-grained sand accumulation PHYSICAL OCEANOGRAPHY VOL. 28 ISS. 1 (2021) 
expands. Depending on the wave direction, its width changes: in the western part from 50-65 m after 6 hours after the wave impact onset to 60-80 m after 12 hours, and in the east - from 105-110 $\mathrm{m}$ after 6 hours to $115-120 \mathrm{~m}$ after 12 hours.

At $t=12 \mathrm{~h}$, the maximum accumulation of coarse-grained material occurs in the eastern part of the coastal zone at the exit from the bay during the waves in the south-southeast direction between 7 and $9 \mathrm{~m}$ isobaths, and in the south and southsouth-west directions - between 6 and $10 \mathrm{~m}$ isobaths. The maximum share of the coarse-grained fraction for the waves of the southeast direction was 0.50 , for the south direction -0.45 , and for the south-southwest -0.43 .

It has been determined that, starting from the first hours of the action of storm waves, fine-grained material is carried out from the coastal zone and accumulates in the sections of the slope (Fig. 3). The maximum concentrations are noted between 12-18 m isobaths, the general redistribution of fine-grained material reaches $30-40 \mathrm{~m}$ isobaths. The width of the area of fine-grained sand accumulation varies depending on the direction of the wave and the time of its impact.

As follows from Fig. 3, regardless of the direction of waves, the areas of maximum concentration of fine-grained sand appear at the eastern coast at the bay exit. The width of the area of this fraction accumulation at $t=12 \mathrm{~h}$ varies from $80-115 \mathrm{~m}$ at the waves of the south-southeast direction to $120 \mathrm{~m}$ at the waves of the south-south-west direction and up to $150 \mathrm{~m}$ at the waves of the south direction.

In the second cycle of numerical experiments, a combination of three fractions of bottom sediments was taken as the initial parameters. The initial distribution of volumetric concentrations of each fraction was determined based on the results of field observations. The initial distribution of sand fractions is shown in Fig. 4.

As was revealed from the calculations, the accumulation of coarse-grained material occurs in the southeastern part of the northern basin, in the northern part of the southern basin, and around the tips of the capes at the exit from the bay (Fig. 5). The transport of coarse and medium-grained material from the coast to the fairway in the northern part of the southern basin is apparently determined by the peculiarities of the coastal orography and wave refraction. Medium-grained material is distributed in a wide strip (95-120 m) at the exit from the bay, in the northern part of the southern basin, and also at the top of the northern part of the bay. The fine-grained fraction accumulates in the northwestern part of the northern basin, in the fairway area and at the exit from the bay.

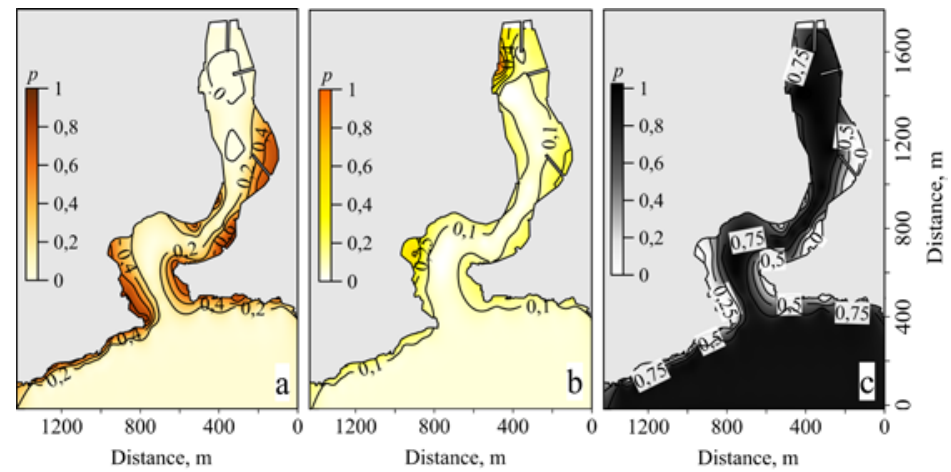

F i g. 4. Initial distribution of the fractions: $a$ - coarse-grained; $b$ - medium-grained and $c$ - finegrained ones 

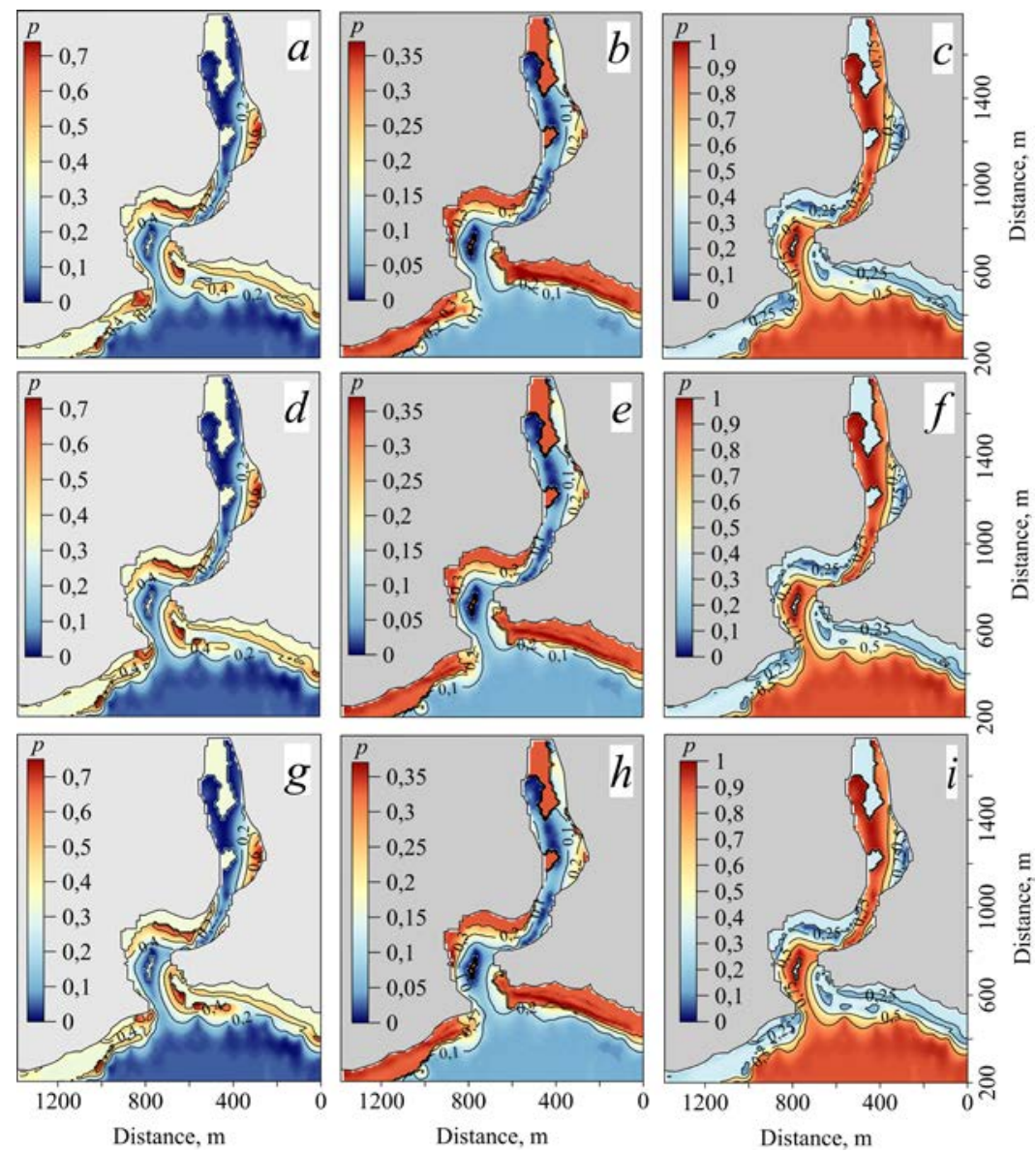

F i g. 5. Spatial distribution of volume concentrations of the coarse-grained $(a, d, g)$, medium-grained $(b, e, h)$ and fine-grained $(c, f, i)$ sand fractions at $t=12 \mathrm{~h}$ at the south-southeast, south and southsouthwest wave directions, respectively

The features of the dynamics of sandy fractions in the southern part of the bay will be considered on the example of the profile at Georgiy Cape (see Fig. 1). Concentrations of coarse-grained sand in the area of 50-90 m decrease, while those of medium-grained sand, on the contrary, increase. It was found that the width of the strip of medium-grained sand accumulation changes in inverse proportion to the width of the coarse-grained sand distribution zone. As the storm develops, it narrows from $50 \mathrm{~m}$ in $4 \mathrm{~h}$ after the onset of wave effect to $30 \mathrm{~m}$ in $12 \mathrm{~h}$.

The concentration of the fine-grained fraction near the coast is minimal. In 0-50 meter section they account for only 0.07-0.1. Changes in concentration, determined by the intensity of waves, are noted in the 50-100 m offshore area between 7.5 and $15 \mathrm{~m}$ isobaths. The concentrations of coarse aleurite only increase with depth.

Like in the calculations in the first cycle of numerical experiments, one of the main parameters that determine the features of the redistribution of sand fractions is the bottom inclination. As an example, we are to consider the section of Georgiy Cape at the exit from the bay during the waves of the south-southwest 
direction (Fig. 6). In the zone of bottom profile active processing, the smoothing of small-scale inhomogeneities of the relief occurs, and three characteristic sections can be distinguished along the inclinations of $\beta$ surface. With a change in the wave period, the inclinations for each site change within insignificant limits.

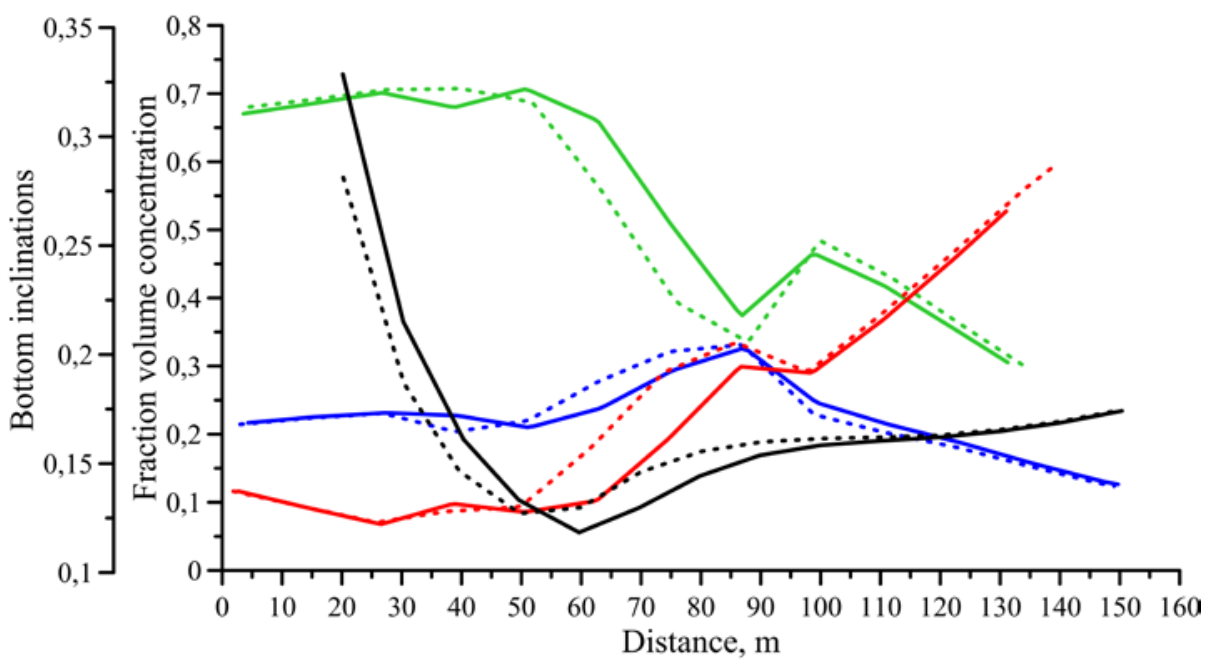

F i g. 6. Features of the sand fractions (coarse-grained - green line, medium-grained - blue line, finegrained - red line) redistribution and dynamics of the bottom inclination angle (black line) at the waves of the south-southwest direction in the Cape Georgia area in 6 (dotted line) and 12 (straight line) hours after the waves began

In the first section $(1.42<\beta<0.12)$, the increased values of bottom inclinationss are noted, as well as their sharp decline in the section, the width of which, depending on the duration of the wave action, varies from $0-50 \mathrm{~m}$ after 6 hours to $0-60 \mathrm{~m}$ in 12 hours. This area is characterized by the maximum accumulation of the coarsegrained fraction. In the second section $(0.13<\beta<0.16)$, a slight increase in the bottom inclinations is observed, as a result of which the sedimentation of smaller fractions occurs. Depending on the wave action duration, the width of the second section varies from $35 \mathrm{~m}$ after 6 hours to $40 \mathrm{~m}$ after 12 hours. Within this section, the maximum concentrations of medium-grained $(0.2-0.35)$ and finegrained (from 0.1 to 0.3$)$ material are noted. The third section $(0.16<\beta<0.19)$ is characterized by a stable increase in the bottom inclination values. The position of this section is determined by the seaward boundary of the second section and the position of the water area boundary where the wave profile processing does not occur.

The modeling results showed that, despite the isolation of the Balaklava Bay northern part from the rough seas (southern sector), under effect of storms of the southern, southeast and south-southwest directions (possible once a year) lasting for 12 hours, the northern basin shows insignificant dynamics of sandy material. A redistribution of bottom sediment fractions from the western coast to the central part of the basin and to the eastern coast of the bay is noted. 
Conclusion. Using XBeach morphodynamic model for the Balaklava Bay water area, two cycles of numerical experiments aimed at studying the features of sandy material redistribution under effect of storm waves of various directions were carried out. In the first cycle of numerical experiments, a homogeneous combination of particle size fractions was applied as the initial parameters for the sediment. The selected values were consistent with the mean values for each fraction of the sediment. In the second cycle of numerical experiments, a combination of three fractions of bottom sediments was taken as the initial parameters. The initial distribution of volumetric concentrations of each fraction was determined based on the results of field observations.

The results of the first numerical experiment showed that in the Balaklava Bay water area the main redistribution of sandy material, caused by storm waves, occurs within the southern basin, as well as at the exit from the bay in the MegaloYalo Gulf coastal zone. First of all, this is determined by the features of the coastal orography, namely, the knee-shaped narrowness separating the northern and southern basins. The location of the areas of coarse-grained material maximum concentrations, as well as the width of the accumulation areas, varied with a change in the wave angle.

The results of the second experiment showed that, despite the isolation of the northern part of the Balaklava Bay from the rough seas, an insignificant redistribution of sandy material occurs under the influence of storms in the northern basin. The movement of fractions of bottom sediments from the western coast to the central part of the basin and to the eastern coast of the bay is noted.

The results of both numerical experiments reveal the fact that one of the main parameters determining the features of sand fractions redistribution is the bottom inclination. It was found that a sharp change in the bottom inclination between 6-7 and 7-8 $\mathrm{m}$ isobaths first leads to the sedimentation of large and medium fractions, and in the area between 9-10 and 10-12 isobaths - to the deposition of finegrained sand.

\section{REFERENCES}

1. Lomakin, P.D. and Popov, M.A., 2011. Oceanological Characteristic and Estimation of the Water Pollution in the Balaklava Bay. Sevastopol: ECOSI-Gidrofizika, 184 p. (in Russian).

2. Verigo, A.A., 1888. Study of the Healing Mud from the Shoal of Balaklava Bay. In: Odessa Balneological Society, 1888. Report on the Activities of the Odessa Balneological Society from 1883 to 1887. Odessa. Iss. 3, pp. 22-26 (in Russian).

3. Mironov, O.G., Kiryukhina, L.N. and Alyomov, S.V., 1999. Complex Ecological Survey of the Balaklava Bay (the Black Sea). Ecology of the Sea, (49), pp. 16-21 (in Russian).

4. Orekhova, N.A., Ovsyany, E.I., Gurov, K.I. and Popov, M.A., 2018. Organic Matter and Grain-Size Distribution of the Modern Bottom Sediments in the Balaklava Bay (the Black Sea). Physical Oceanography, 25(6), pp. 479-488. doi:10.22449/1573-160X-2018-6-479-488

5. Tikhonova, E.A., Kotelyanets, E.A. and Gurov, K.I., 2019. Content of Organic Compounds and Trace Metals in Bottom Sediments of the Balaklava Bay (The Black Sea). Ecological Safety of Coastal and Shelf Zones of Sea, (3), pp. 82-88 (in Russian).

6. Ovsyany, E.I., Kotelyanets, E.A. and Orekhova, N.A., 2009. Arsenic and Heavy Metals in the Bottom Sediments of the Balaklava Bay (Black Sea). Physical Oceanography, 19(4), 254. https://doi.org/10.1007/s11110-009-9048-4 
7. Kotelyanets, E.A., Gurov, K.I., Tikhonova, E.A. and Kondratev, S.I., 2019. Pollutants in Bottom Sediments in the Balaklava Bay (the Black Sea). Physical Oceanography, 26(5), pp. 414-424. doi:10.22449/1573-160X-2019-5-414-424

8. Roelvink, D., Reniers, A., Van Dongeren, A., van Thiel de Vries, J., McCall, R. and Lescinski, J., 2009. Modelling Storm Impacts on Beaches, Dunes and Barrier Islands. Coastal Engineering, 56(11-12), pp. 1133-1152. https://doi.org/10.1016/j.coastaleng.2009.08.006

9. Van Rijn, L.C., Tonnon, P.K. and Walstra, D.J.R., 2011. Numerical Modelling of Erosion and Accretion of Plane Sloping Beaches at Different Scales. Coastal Engineering, 58(7), pp. 637655. https://doi.org/10.1016/j.coastaleng.2011.01.009

10. Bakhtyar, R., Dastgheib, A., Roelvink, D. and Barry, D.A., 2016. Impacts of Wave and Tidal Forcing on 3D Nearshore Processes on Natural Beaches. Part I: Flow and Turbulence Fields. Ocean Systems Engineering, 6(1), pp. 23-60. http://dx.doi.org/10.12989/ose.2016.6.1.023

11. Leont'yev, I.O., 2018. Modeling a Shore Profile Formed by Storm Cycle Impact. Oceanology, 58(6), pp. 892-899. https://doi.org/10.1134/S0001437018060085

12. Leont'yev, I.O., 2019. Storm-Induced Deformations of a Barred Beach Slope. Oceanology, 59(1), pp. 115-122. https://doi.org/10.1134/S0001437019010089

13. Kuznetsova, O.A. and Saprykina, Y.V., 2019. Modeling the Dynamics of a Sand Beach Governed by the Wave and Underwater Bar Interaction. Geomorphology RAS, (3), pp. 57-67. https://doi.org/10.31857/S0435-42812019357-67 (in Russian).

14. Kubryakov, A.I. and Popov, M.A., 2005. Modeling of Circulation and Propagation of Contaminating Impurities in the Balaklava Bay. Physical Oceanography, 15(3), pp. 180-191. https://doi.org/10.1007/s11110-005-0040-3

15. Fomin, V.V. and Repetin, L.N., 2005. Numerical Simulation of Wind Currents and Propagation of Impurities in the Balaklava Bay. Physical Oceanography, 15(4), pp. 232-246. https://doi.org/10.1007/s11110-005-0045-y

16. Gurov, K.I. and Fomin, V.V., 2017. Dynamics of Sediments Grainsize in Limensky Gulf. In: E. Özhan, Ed., 2017. Proceedings of the Thirteenth International MEDCOAST Congress on Coastal and Marine Sciences, Engineering, Management and Conservation, MEDCOAST 17, 31 Oct - 04 Nov 2017. Dalyan, Mugla, Turkey: Mediterranean Coastal Foundation. Vol. 2. pp.925-935. Available at: https:/www.researchgate.net/publication/321035650_The_dynamics_of_sediments_grainsize_in_Limensky_Gulf [Accessed: 21 January 2021].

17. Sidorenko, A.V., ed., 1969. Geology of the USSR. Vol. 8. Crimea, Part 1: Geological Structure. Moscow: Nedra Publishing, 576 p. (in Russian).

18. Zenkovich, V.P., 1958. Shores of the Black and Azov Seas. Moscow: Geografgiz, 374 p. (in Russian).

19. Repetin, L.N., Belokopytov, V.N. and Lipchenko, M.M., 2003. Winds and Wave Perturbations in the Southwest Crimean Coast. In: MHI, 2003. Ecological Safety of Coastal and Shelf Zones and Comprehensive Use of Shelf Resources. Sevastopol: MHI. Iss. 9, pp. 1328 (in Russian).

20. Roelvink, D., van Dongeren, A., McCall, R., Hoonhout, B., van Rooijen, A., van Geer, P., de Vet, L., Nederhoff, K. and Quataert, E., 2015. XBeach Technical Reference: Kingsday Release. Model description and reference guide to functionalities: Report. Deltares: Delft, 141 p. doi:10.13140/RG.2.1.4025.6244

21. Fomin, V.V. and Polozok, A.A., 2020. Wind Wave Regime in the Area of Balaklava Bay. Ecological Safety of Coastal and Shelf Zones of Sea, (2), pp. 53-67. doi:10.22449/2413-55772020-2-53-67 (in Russian).

22. Gurov, K.I., Ovsyany, E.I., Kotelyanets, E.A. and Konovalov, S.K., 2015. Factors of Formation and Features of Physical and Chemical Characteristics of the Bottom Sediments in the Balaklava Bay (the Black Sea). Physical Oceanography, (4), pp. 46-52. doi:10.22449/1573-160X-2015-4-46-52

23. Zenkovich, V.P., 1946. [Dynamics and Morphology of Sea Coasts. Part 1: Wave Processes]. Moscow; Leningrad: Marine transport, 496 p. (in Russian). 
About the authors:

Konstantin I. Gurov, Junior Research Associate, Marine Hydrophysical Institute of RAS (2 Kapitanskaya str., Sevastopol, 299011, Russian Federation), ORCID ID: 0000-0003-3460-9650, ResearcherID: L-7895-2017, gurovki@gmail.com

Vladimir V. Fomin, Head of Department of Computational Technologies and Mathematical Modeling, Marine Hydrophysical Institute of RAS (2 Kapitanskaya str., Sevastopol, 299011, Russian Federation), Dr. Sci. (Phys.-Math.), ORCID ID: 0000-0002-9070-4460, v.fomin@ukr.net

Contribution of the co-authors:

Konstantin I. Gurov - formulation of purposes and objectives of the study, analysis of literature data, analysis and preparation of initial conclusions, processing and description of the research results, qualitative analysis of the results and their interpretation, preparation of the text of the paper

Vladimir V. Fomin - correction of the mathematical model and carrying out the calculations, participation in the discussion of the paper materials

All the authors have read and approved the final manuscript.

The authors declare that they have no conflict of interest. 